\title{
COPYRIGHT MANAGEMENT SYSTEMS
}

\section{Accessing the power balance}

\author{
Carlisle E. George \\ Middlesex University, UK, c.george@mdx.ac.uk
}

\begin{abstract}
This paper first examines technical and legal issues surrounding Copyright Management Systems (CMS). It then examines the rationale for use of these systems and some accompanying criticisms. It argues that there are compelling economic reasons for controlling access to, and use of copyrighted material, especially in light of digital technology and the Internet. It also argues that CMS have very undesirable qualities which raise concerns about social accountability. They can exert strong control over access to material, invade privacy and deprive the public domain of valuable resources (hence affecting innovation) echoing aspects of eighteenth century Blackstonian ideology. The paper concludes that the present state of affairs in which CMS has increased the power to rights-holders may be detrimental to the development of human society. Technology and the law appear to have colluded to potentially stifle innovation, hence producing no ultimate winners in the future.
\end{abstract}

\section{INTRODUCTION}

The advent of digital technology has meant that digital content can be easily copied without loss of quality and also easily distributed (via the Internet) throughout the world. Famous legal battles such as A\&M Records Inc $v$ Napster ${ }^{1}$, demonstrate the potential threat that copyright holders feel from digital copying, especially their inability to control the dissemination of their work. Rights-holders, however, have fought back by using technological measures to protect their work. This has posed a dilemma. On one hand rights holders aim to protect their work from unauthorised copying

${ }^{1}$ A\&M Records, Inc and others $v$ Napster, Inc D.C. No. CV-99-05183-MHP. Napster facilitated the worldwide distribution of music via their peer-to-peer file sharing system. They were found guilty of contributory and vicarious infringement of copyright. 
and use, on the other hand consumers/users desire greater freedom to use these works.

\section{COPYRIGHT MANAGEMENT SYSTEMS (CMS)}

CMS are technological measures which aim to protect copyrighted works. These systems range from digital watermarking and web tracking systems $^{2}$ to more sophisticated access-control systems. The former seeks to investigate infringement after the event, while the latter seeks to prevent infringement and control access. This paper will focus on the latter.

\subsection{Technical Issues}

Access control systems prevent unauthorised access to copyrighted works and allow licensed use of works under certain terms and conditions. Some access-control CMS essentially consist of content and rights identification facilities and a facility for licensing ${ }^{3}$. More advanced systems, for example, trusted systems ${ }^{4}$ and Digital Rights Management Systems ${ }^{5,6,7}$ use software or a semi-conductor chip in hardware (e.g. computers, audio/video players) which controls access by being able to encrypt and decrypt the copyrighted work. The software or chip usually contains instructions which enables it to permit or deny access to the protected work, impose usage rights (e.g. permission to copy, transfer. loan, play, print), specify cost and other terms/ conditions of use. Hence rights-holders can have total control over any interaction between content seekers and the content. Distribution of protected content may be via client/server technology (Internet), digital audio broadcasting or CD's among others.

${ }^{2}$ E.g. see http://www.digimarc.com/ for a review of digital watermarking and tracking techniques

${ }^{3}$ Gervais, D.(1999). Electronic Rights Management and Digital Identifier Systems. The Journal of Electronic Publishing March, 1999 Volume 4, Issue 3. Stefik, M.(1997).

Trusted

Systems. http://www.hackvan.com/pub/stig/articles/trusted-systems/0397stefik.html

5 Glass, B. (2003). What does DRM really mean? , PC Magazine. April 8, 2003.

${ }^{6}$ Sellers, C. (2003). Digital Rights Management Systems: Recent European Issues. Ent. L.R. 2003, 14(1), 5-9

${ }^{7}$ Lui, Q et al (2003). Digital Rights Management for Content Distribution. AISA2003, Conferences in Research \& Practice in Information technology, Vol 21. C. Johnson, P. Montague \& C SteKette (Eds) 


\subsection{Legal Issues}

The debate about whether technological protection systems stifle innovation, results not only from the technology itself (architecture) but also from the strong legal protection given to these systems. Hence content is protect by both law and architecture ${ }^{8}$ or a hierarchy/design hybrid. ${ }^{9}$ Any discussion relating to the said debate, therefore, necessitates a look at the relevant anti-circumvention legislation in the EU (Directive 2001/29/EC, "Directive"10) and US (The Digital Millennium Copyright Act 1998 "DMCA"11). Both legislative frameworks are largely consistent with the WIPO Copyright Treaty $1996 .{ }^{12}$

Under the DMCA (US Code Title 17 Copyrights), three major acts are prohibited namely: circumventing a technological measure that controls access to "a work protected under this title"13; manufacturing or trafficking in any technology, device or service which is primarily designed for the purpose of circumventing ${ }^{14}$ a technological measure that (a) controls access to "a work protected under this title"15 or (b) protects the rights of a copyright owner. ${ }^{16}$ The DMCA also states that other rights (e.g. limitations, defences, fair use) are not affected ${ }^{17}$ and gives seven specific exemptions to the act of circumventing a technical protection system. ${ }^{18}$

${ }^{8}$ Lessig, L. (1999). Code and other laws of cyberspace. NY, Basic Boooks.

${ }^{9}$ Murray, A \& Scott, C. (2002). Controlling the New Media: Hybrid Responses to New Forms of Power. The Modern Law Review 2002, Vol 65, No 4.

${ }^{10}$ Directive 2001/29/EC on the harmonization of certain aspects of copyright and related rights in the information society. See http://www.patent.gov.uk/about/consultations/eccopyright/annexb.htm

${ }^{11}$ DMCA 1998. See: http://www.copyright.gov/legislation/dmca.pdf

${ }^{12}$ WIPO Treaty 1996 See: http://www.gseis.ucla.edu/iclp/wipol.htm

The WIPO Copyright Treaty (WCT) 1996 focused on prohibiting the act of circumvention where a technological measure "restrict acts, in respect of their [copyright holder] works, which are not authorised by the authors concerned or permitted by law" (Article 11)

${ }^{13}$ Section 1201(a)(1)

14 Circumvention means "avoiding, bypassing, removing, deactivating, or otherwise impairing a technological measure". DMCA Section 1201(b)(2)(A).

${ }^{15}$ DMCA Section 1201(a)(2)

${ }^{16}$ DMCA Section 1201(b)

${ }^{17}$ DMCA Section 1201 (c)

${ }^{18}$ DMCA Section 1201(d)-(j) These specific exemptions pertain to: allowing non-profit libraries and education institutions to make a determination (in good faith) whether to acquire a copy of the work; activities of law enforcement and government; reverse engineering to achieve interoperability of a computer program; encryption research to investigate flaws of encryption technologies; preventing access of minors to Internet material; protecting personally identifying information; and testing security flaws and weaknesses. 
The EU Directive, requires that Member States "provide adequate protection against the circumvention of any effective technological measures", which prevent or restrict acts not authorized by the rights holder. ${ }^{19}$ This includes prohibiting the manufacture, importation or possession of any technological device, product or service whose primary function is to circumvent a technological protection measure. The Directive also requires Member States to take appropriate measures to ensure that beneficiaries of exceptions and limitations ${ }^{20}$ provided by national laws ${ }^{21}$ are given the means to benefit from these exceptions and limitations.

The effects of the laws above will be discussed later. They prohibit the manufacture or importation of anti-circumvention devices, making it impossible for someone to engage in circumvention, whatever the motive. The DMCA in particular has caused enormous controversy and debate regarding its effect on research and innovation.

\section{STRONG PROTECTION VERSUS GREATER FREEDOM OF ACCESS}

A major reason for the existence of copyright law is to reward rights holders for their work, and to give an incentive to create works in the future. The advent of digital technologies and the Internet, however, have facilitated easy copying, distribution and sharing of information including copyrighted works. For rights holders, stopping the unauthorised reproduction and distribution of their work have become a major concern especially as this translates to a loss of revenue. The Commercial Piracy Report 2003 of the International Federation of the Phonographic Industry, (representing 1500 record companies in 70 countries) reported global sales of pirated CD's totalling US $\$ 4.6$ billion in 2002. ${ }^{22}$ Estimates of money lost in 2001 from pirated software in India amounted to US\$24 million. ${ }^{23}$ The Economist predicts that "Peer-to-peer file sharing will deprive the [music] industry of

\footnotetext{
${ }^{19}$ Article 6(1)

${ }^{20}$ This would imply exceptions and limitations (Article 5) to the reproduction right (Article 2) and the right of communication to the public (Article 3) (e.g. private use, public libraries, broadcast Organizations) should be allowed. Right holders, however can limit the number of reproductions for private use given under Article 5(2)(b).

${ }^{21}$ Directive 2001/29/EC, Article 6(4).

${ }^{22}$ Commercial Piracy Report 2003. http://www.ifpi.org/site-content/antipiracy/piracy2003the-key-facts.html

${ }^{23} \mathrm{http}: / /$ www.blonnet.com/2002/08/06/stories/2002080600920700.htm
} 
US $\$ 4.7$ billion of revenues in $2008 " .{ }^{24}$ Issues such as the above, provide justification for technological measures to control the dissemination and reproduction of works, allowing the copyright owner to dictate usage and access rights. Further, prohibiting circumvention of such measures has been justified by the economic argument that infringement causes an uplift in the price of copyrighted works, hence preventing infringement allows more public access to works at the lower price. ${ }^{25}$

Opponents of strong protection as afforded by CMS, see these systems as going against the spirit of copyright law, which is meant to facilitate the development of creative works for the public good (or benefit of society ${ }^{26}$ ), and not to confer absolute protection. ${ }^{27} \mathrm{CMS}$, accompanying laws against circumvention and contractual restrictions have fortified works, resulting in even stronger protection (for works) than originally intended by copyright law. This stronger protection is manifested in the extension of: the term of the duration of copyright and the scope of copyright.

\subsection{Extension of Duration of Copyright}

Use of a CMS may mean that works can be locked away under technological protection for longer than copyright law allows. This violates the intention of copyright law, to offer protection for a limited amount of time, after which the work becomes available for free use by the public (i.e. becomes part of the "public domain" ${ }^{28}$ ).

The issue of the public domain and limiting the duration of copyright has been one of historical debate. English theorists of property such as Hobbes and Locke, consistently argue ${ }^{29}$ for absolute rights of owners and against

${ }^{24}$ The Economist (2003), Is the threat of online piracy receding? The Economist ,Oct 2003. $\mathrm{http}: / /$ www.economist.com/business/displayStory.cfm?story_id=2177244

${ }^{25}$ (NII Group) 1995 Intellectual property and National Information Infrastructure: The Report of the Working Group on Intellectual property Rights. ISBN 0-9648716-0-1.

${ }^{26}$ Rice, D. (2002) : Copyright as Talisman: Expanding 'Property' in Digital Works, 16(2) International Review of Law, Computers \& Technology 113.

${ }^{27}$ Copyright protection is subject to a limitation period, fair use/dealing, first sale \& other limitations

28 " Public domain refers to refers to works and parts of works which a copyright owner does not own... ideas, insubstantial parts of works, works which are too insubstantial to attract copyright protection, substantial parts of works which are works used for the purpose of fair dealing, and works whose copyright has expired". Waelde, C. (2001) Infra note 47

${ }^{29}$ Travis, H.(2000): Pirates of the Information Infrastructure: Blackstonian Copyright and the First Amendment 15 Berkeley Technology Law Journal. http:/www.law.berkeley.edu/journals/btlj/articles/vol15/travis/travis.html 
any rights by the public in common lands (commons $\mathrm{s}^{30}$ ). This argument was grounded in 'propertarian ideology' which advocated that private property rights and national wealth, weighted against the public right in the commons. ${ }^{31}$ In particular enclosures of commons were justified by arguments that public rights in the commons were not really rights as such, use of the commons was wasteful and that utilitarian and economic benefits would arise from more adequate use of such lands (e.g. by merchant farmers). ${ }^{32}$ In shifting 'propertarian ideology' from the physical to intellectual commons, another theorist William Blackstone argued for perpetual common-law copyright giving owners unlimited exclusivity to control their works. ${ }^{33}$ In 1710, amidst much opposition from booksellers, the Statute of Anne, granted statutory rights to copyright holders but these rights were limited both in duration and scope. The fight for a perpetual commonlaw copyright, however, continued, culminating in the House of Lords decision in Donaldson and Becket $(1774)^{34}$ which rejected the notion of perpetual common-law copyright.

In the US, the founding fathers were against perpetual monopolies and supported the idea of limited copyright. As a result of the English Donaldson case, congress enacted a copyright clause in the US Constitution which restricted authors exclusive rights as to "purpose, subject matter, beneficiaries and duration". ${ }^{35}$

Presently, limitations on the duration of copyright continue to be the position in both UK and US copyright law. ${ }^{36}$

\subsection{Extension of the Scope of Copyright}

The extension of the scope of copyright by CMS is primarily manifested by the restriction on access to a work for "fair use" (US) or "fair dealing" (UK/EU) purposes. The doctrines of "fair use" and "fair dealing" have traditionally allowed use of extracts of copyrighted material under certain circumstances without authorization. UK/EU "fair dealing" is limited to a

${ }^{30}$ Lessig describes the commons as "a resource to which anyone within the relevant community has a right without obtaining the permission of anyone else." p19-20, Lessig, L. (2001). The Future of Ideas: The Fate of the Commons in a Connected World . NY, Random House

${ }^{31}$ See Travis, H. (2000) supra 29

${ }^{32}$ Ibid

${ }^{33}$ Ibid

3498 Eng. Rep. 257 (H.L.1774).

${ }^{35}$ See Travis, H.(2000) supra 29

${ }^{36}$ UK, Copyright and Patents Act 1988 as amended and US Copyright Act 1976 as amended 
list of purposes stipulated by law (research and private study, criticism and review, news reporting). ${ }^{37}$ US "fair use" ${ }^{938}$ does not entail an exhaustive list of purposes but is determined mainly by reference to four factors namely ${ }^{39}$ : the purpose and character of use (e.g., commercial, non-profit educational purposes); the nature of the copyrighted work; the amount and substantiality of the portion used in relation to the protected work as a whole; and the effect of the use upon the potential market.

Most UK "fair dealing" purposes, would qualify as "fair use" under US law. Use of CMS raises fair use/dealing concerns from two perspectives, namely the technology and the law.

Regarding technology, with CMS, protected works are inaccessible unless a fee is paid. Further it is perhaps beyond the state of the art to design a system to adequately allow fair use. ${ }^{40}$ Such a system would need knowledge of the circumstances of the use (e.g. domestic vs commercial) and complex artificial intelligence techniques to apply the US four-factor "fair use" test ${ }^{41}$ (requiring an economic analysis of markets). ${ }^{42,43}$

With regard to the law, while the DMCA and EU Directive 2001/29/EC attempt to address fair use/dealing concerns, it is argued that these provisions are perhaps not very effective. First it is worthwhile to note, that the DMCA and Directive differ in their approaches to fair use/dealing. The DMCA provides exemptions to circumvention under certain circumstances. ${ }^{44}$ This, however, is nullified (to a great extent) by the prohibition on the manufacture or trafficking of anti-circumvention devices. The Directive, differs from the DMCA by tackling the problem at the earlier stage (before

${ }^{37}$ Copyright, Design and Patents Act (1988) (CDPA), Sections 29, 30. http://www.jenkinsip.com/patlaw/cdpal.htm

${ }^{38}$ For a good discussion of 'fair use' see Landau, M (2002) : Digital Downloads, Access Codes and US Copyright Law [2002] 16(2) International Review of Law, Computers \& Technology 149.

${ }^{39}$ Title 17 US Code, Ch 1, Section 107, see: http://www.copyright.gov/title17/index.html. Also note that the Berne Convention contains a three-step test for limitations and exceptions which such tests are based on.

${ }^{40}$ Felten, E. (2003). A Skeptical View of DRM and Fair Use. Communications of the ACM, Vol 46(4).

${ }^{41}$ Supra note 39

${ }^{42}$ Felten, E (2003) supra 40

${ }^{43}$ Also see Erikson,J. (2003). Fair Use, DRM and Trusted Computing. Communications of the ACM, Vol 46(4). Erikson contends that "in the case of fair use, no explicit set of rules can be implemented and automatically evaluated by computing systems" p.38.

${ }^{44}$ DMCA Section 1201(d)-(j) supra note 18 
lock-up). ${ }^{45}$ It requires Member States to ensure that rights holders make available to a beneficiary of an exception or limitation (e.g. fair dealing), the means of benefiting from that exception or limitation. ${ }^{46}$ Ideally, this would involve allowing for fair dealing principles when designing CMS. As discussed earlier, this may not be adequately functional with the state of the art. Additionally, EU Member States can take measures where rights holders fail to provide for private copying. For example in the UK, an application can be made to the Secretary of State, if requests for copies has been exhausted. This procedure, however, appears to be burdensome for the average member of the public.

A second legal issue regards the legitimacy of contractual restrictions in digital licences of $\mathrm{CMS}^{47}$ In many instances they prevent uses of works which may be legitimate under copyright law. This therefore results in further protection via private law.

A third legal issue concerns the restrictions on reverse engineering and decompilation (implicit in the regulatory framework) and the potential effects on software security and privacy. Reverse engineering of software involves decompiling software (i.e. converting it from a low level language to a high level language) to understand how it works. ${ }^{48}$ In US, the case of Sega Enterprises Ltd. v. Accolade Inc., ${ }^{49}$ established the legality of decompilation (as a fair use) if carried out to gain access to unprotected functional elements of a program, in order to create interoperable systems. Under the DMCA (Section 1201(f)) reverse engineering is allowed as a defence (to circumvention of an access control measure) where it is necessary to enable interoperability of an independently created program with other programs. In the process of reverse engineering, copyright infringement must not occur nor should any other US laws be violated. In the EU while decompilation is not listed as a fair dealing purpose, under Directive $91 / 250 / \mathrm{EEC}^{50}$ decompilation of a computer program is allowed by

${ }^{45}$ Duollier, S. (2003). Fair Use by Design in the European Copyright Directive of 2001.

Communications of the ACM, Vol 46(4).

${ }^{46}$ Directive 2001/29/EC, Article 6(4).

${ }^{47}$ Cohen, J (1997). Some Reflections on Copyright Management Systems and Laws Designed to Protect Them 12 Berkeley Technology Law Journal http://www.law.berkeley.edu/journals/btlj/articles/vol12/Cohen/html/reader.html

${ }^{48} \mathrm{http}: / / \mathrm{cse}$. stanford.edu/class/cs201/projects-99-00/intellectual-propertylaw/reverse_engineering.htm

${ }^{49}$ Sega Enterprises Ltd. v. Accolade Inc., http://digital-lawonline.info/cases/24PQ2D1561.htm

so Directive $(91 / 250 / \mathrm{EEC})$ on the legal protection of computer programs See: http://europa.eu.int/ISPO/legal/en/ipr/software/software.html 
a lawful user "to obtain the information necessary to achieve the interoperability of an independently created computer program with other programs". ${ }^{51}$ Several additional restrictions are given in the Directive including that decompilation should not be used to make a program similar to the decompiled program or to violate any acts restricted by copyright.

The restrictions on reverse engineering and decompilation are important because there are legitimate reasons (other than what is legally allowed) for decompiling CMS. An important reason is to evaluate CMS software security and functionality. Without being permitted to legally decompile CMS software, users may not be able to find software bugs, security flaws or hidden functionality (such as user profiling for advertising purposes or other acts of privacy invasion) which may exist.

\section{DISCUSSION}

From the previous discussion there appears to be legitimate reasons (e.g. loss of revenue as pointed out earlier) why CMS are employed. The threat of the Internet and digital technologies present a real problem of control for rights holders. CMS, however, do not reflect the spirit of copyright law especially with regard to the limitation period and fair use/dealing. They also allow universal control of copyright works. All access to works must be through the granting of permission and the technology exists in some systems to track and monitor individual users. This raises concerns about privacy and data protection. ${ }^{52}$ There appears to be a real concern that the power balance in CMS may be too much in favour of a strong control by authors. This has the potential to deter innovation and discourage potential competitors in various markets.

In addition to controlling access to copyrighted works, CMS can restrict access to works which either do not qualify for copyright protection or have exhausted their period of copyright protection. This therefore, can deprive the public domain of valuable resources. Hence use of CMS may result in some 'public domain' and other creative works inaccessible except to those who are able to pay for them..$^{53}$ Public domain (and creative works) are a key

${ }^{51}$ Ibid Article 6.

${ }^{52}$ Cohen, J (1997) supra 47

${ }^{53}$ Waelde, C. (2001). The Quest for Access in the Digital Era: Copyright and the Internet. The Journal of Information, Law and Technology (JILT), 2001(1). http://elj.warwick.ac.uk/jilt/01-1/waelde.html 
to innovation, since new ideas are formed from existing ideas. ${ }^{54}$ Also new creative works incorporate and build on existing works, hence any barrier to accessing existing works is a barrier to innovation. The more a creator can borrow from previous works (e.g. exercising fair use/dealing), the lower the cost of creating new works. ${ }^{55}$ Conversely, the harder it is to access works (e.g. access \& licensing costs), the more expensive it becomes to create new works, potentially resulting in a lower number of new works created ${ }^{56}$. It follows that the longer works are kept from the public domain, the higher the cost of creating new works. This inevitably results in less innovation and by extension less competition in relevant markets. The effect of a tight control on intellectual property on innovation can be seen from many past examples. The US company AT\&T's control over the telephone network, and Microsoft's restriction on access to its source code ${ }^{57}$ are historical examples where control and lack of access to information stifled innovation and competition. In contrast, many innovative developments (e.g. Linux) have been made through the 'Open Source' software movement. ${ }^{58}$

Responding to the claim that CMS may result in inaccessibility to the public domain, it has been argued that technological protection measures are only applied to copies of works in the public domain and not to the underlying work itself. ${ }^{59}$ Hence although there may be restrictions on what can be done with a work by technical means (e.g. making digital copies), this does not prevent use of the work by other means (e.g. quoting, manual copying).$^{60}$ Prohibition of circumvention therefore focuses on access to a work, via technological means. While plausible, this argument does not address the fact that it may be difficult or impossible to access 'underlying works' in the first place. Consumers may find it difficult to gain access due to geographical location or simply the inability to locate these works.

${ }^{54}$ Lessig, L. (2001). The Future of Ideas: The Fate of the Commons in a Connected World . NY, Random House.

${ }^{55}$ This economic analysis is an adaptation of the Landes and Posner's argument regarding the counterproductivity of copyright protection when the level of protection raises the cost of creating new works. See, p. 332, Landes, W. \& Posner, R (1989). An Economic Analysis

${ }^{56} \mathrm{Ibid}$ of Copyright Law. Journal of Legal Studies, Vol XVIII (June 1989).

${ }^{57}$ See Lessig, L (2001) supra note 54

${ }^{58}$ DiBona, C, Ockman S, \& Stone, M (1999) (Eds). Open Sources: Voices from the Open Source Revolution. O'Reilly \& Associates.

${ }^{59}$ See (NII Group) supra note 25

${ }^{60}$ Ibid 
The DMCA in particular has stirred much debate ${ }^{61}$ and many have voiced concerns regarding its effect on innovation ${ }^{62}$. The ACM's US Public Policy Committee have raised concerns that prohibition on circumvention will "produce a chilling effect on US scientific and research enterprise". ${ }^{63}$ Also that researchers may not feel free to publish their research which may affect the academic community as a whole. ${ }^{64}$ These issues are underscored by several previous US legal cases. In the Elcomsoft Case ${ }^{65}$, Dmitry Sklyarov was prosecuted under the $\mathrm{DMCA}^{66}$ for developing the Advanced eBook Processor software which enabled legitimate owners of Adobe's eBook format to change to the more common Portable Document Format (PDF). In the DeCSS Case ${ }^{67}$, defendants were found liable under the DMCA ${ }^{68}$ after publishing details of a program (DeCSS) ${ }^{69}$, developed to decrypt the Content Scrambling System (CSS) for DVD's. In the Felton Case ${ }^{70}$, professor Edward Felton, a Princeton University computer scientist was prevented from presenting his research findings on how to defeat technology for protecting music files. He was threatened by the recording industry for possible violations under the DMCA. ${ }^{11}$ Felton commented that the DMCA outlaws the scientific method, which involves analysing technical claims by others and presenting evidence from these analyses. In effect, the DMCA

${ }^{61}$ For a critique of the DMCA see Samuelson, P. (1999). Intellectual Property and the Digital Economy: Why the Anti-Circumvention Regulations Need to Be Revised 14 Berkeley Technology Law

Journal. http://www.law.berkeley.edu/journals/btlj/articles/vol14/Samuelson/html/reader.html

${ }^{62}$ For example see Blaze, M (2001). Matt Blaze's declaration regarding the Felton DMCA case http://www.pairlist.net/pipermail/ietf-idrm/2001-August/000106.html

${ }^{63}$ Grove, J (2003). Legal and Technological Efforts to Lock up Content Threaten Innovation. Communications of the ACM, 2003, 46(4)

${ }^{64}$ Ibid. Many US scientists have sought legal advice on whether their current research violates the DMCA and some scientists have not published their scholarly work for fear of legal action.

${ }^{65}$ U.S. v. ElcomSoft \& Sklyarov. See:http://www.eff.org/IP/DMCA/US_v_Elcomsoft

Sklyarov helped create the Advanced eBook Processor (AEBPR) software for his employer Elcomsoft.

AEBPR which allowed legitimate eBook owners to translate from Adobe's secure eBook format into the more common Portable Document Format (PDF)..

${ }^{66}$ ElcomSoft \& Sklyarov faced four criminal charges of circumvention offenses, and aiding and abetting circumvention offenses, under the DMCA section 1201 and one charge of conspiracy

${ }^{67}$ Universal City Studios Inc $v$ Shawn Reimerdes (2000) 111 F. Supp. 2d 294. Also see: http://www.nysd.uscourts.gov/courtweb/pdf/00-01149.PDF

${ }^{68}$ Section 1201(a)(2)

${ }^{69}$ The DeCSS program allowed DVD's to be played on the Linux operating system rather than on Windows/Mac (for which it was developed)

${ }^{70}$ Felten v. RIAA see: http://www.eff.org/Cases/Felten_v_RIAA/

${ }^{71}$ See: RIAA/SDMI Legal Threat Letter (April 9, 2001) to Professor Felton http://www.eff.org/Legal/Cases/Felten_v_RIAA/20010409_riaa_sdmi_letter.html 
prevents the flow of information thereby blocking insight into what has been done and prevents authoritative dialogue on research issues. ${ }^{72}$

\section{CONCLUSION}

There are compelling economic reasons for controlling access to copyright material, especially in light of digital technology and the Internet. However, use of CMS (aided by legislation and contract law) appears to have tipped the balance of control too strongly in favour of copyright holders. The public domain is being deprived of valuable resources, an unfortunate development which echoes some aspects of eighteenth century Blackstonian ideology. There is therefore the need for some social accountability in the use of CMS, since they appear to go against the original sprit of copyright law, impinge on privacy and adversely affect innovation. The threat to innovation is of particular concern since innovation rarely takes place in a vacuum, therefore, unencumbered access to previous work is critical to developing future work. Criminal penalties under laws like the DMCA and EU Copyright Directive are too great a price for researchers and market competitors to pay. Very few are willing to become martyrs. Innovation in the future may be a thing of the past.

72 Huang, D (2002). Felton, Academic Freedom, DMCA http://www.duke.edu/ dsh4/cps182/cps182-paper1 take2.doc 